\title{
ON THE REVERSE CONVOLUTION INEQUALITIES FOR THE KONTOROVICH-LEBEDEV, FOURIER COSINE TRANSFORMS AND APPLICATIONS
}

\author{
PHAM VAN HOANG
}

\begin{abstract}
In this paper, we investigate some reverse weighted $L_{p}$-norm $(p>1)$ inequalities for convolutions related to Kontorovich-Lebedev, Fourier cosine transforms. A class of intergrodiffirential equations involing in Bessel operator are considered. The estimate of scratted acoustic field is established.

Mathematics subject classification (2010): 35A22, 44A35, 26D15, 26D10, 45E10, 45J05, 33E30,

Keywords and phrases: Integral transforms, weighted $L_{p}$ inequality, reverse Hölder inequality, KontorovichLebedev transform, integro-differential equations.
\end{abstract} $65 \mathrm{R} 10$.

\section{REFERENCES}

[1] M. Abramowitz And I. A. STEgun, Handbook of Mathematical Functions with Formulas, Graphs, and Mathematical Tables, National Bureau of Standards, Applied Mathematics Series 55, Washington, 1979.

[2] D. S Jones, The Theory of Electromagnetism, Pergamon Press, London, 1964.

[3] N. T. Hong, Inequalities for Fourier cosine convolution and applications, Integral Transforms Spec. Funct. 62, 10 (2010), 755-763.

[4] N. T. Hong, P. V. HoAng, AND V. K. TuAn, The convolution for the Kontorovich-Lebedev transform revisited, J. Math. Anal. Appl. 440, 1 (2016), 369-378.

[5] V. A. KAKICHEV, On the convolution for integral transforms, Izv. Vyssh. Uchebn. Zaved. Mat. 2, 1 (1967), 53-62 (In Russian).

[6] N. D. V. Nhan, D. T. DUC, AND V. K. TUAN, Reverse weighted $l_{p}$-norm inequalities for convolution type integrals, Armenian. Journ. of. Amth 2, 3 (2009), 77-93.

[7] S. SAITOH, A fudamental inequality in convolution of $L_{2}$ functions on the half line, Proc. Amer. Math. 91, 2 (1984), 285-286.

[8] S. SAitoh, Inequalities in the most simple Sobolev space and convolution of $L_{2}$ functions with weights, Proc. Amer. Math. 118, 2 (1993), 515-520.

[9] S. Saitoh, V. K. TUAn, AND M. YAmamoto, Reverse weighted $L_{p}$-norm inequalities in convolutions, J. of Ineq. In Pure and App. Math. 1, 1 (2000), 1-11.

[10] S. Saitoh, V. K. TUAn, AND M. YAmamoto, Reverse convolution inequalities and applications to inverse heat source problems, J. of Ineq. In Pure and App. Math. 3, 5 (2002), 1-11.

[11] S. Saitoh, V. K. Tuan, And M. Yamamoto, Convolution inequalities and Applications, J. of Ineq. In Pure and App. Math. 4, 3 (2003), 1-8.

[12] T. Tuan, N. T. Hong, And P. V. HoAng, Generalized convolution for the Kontorovich-Lebedev, Fourier transforms and applications to acoustic fields, Acta Math. Vietnam. 42, 2 (2016), 355-367.

[13] L. XIAO-HuA, On the inverse of Hölder inequality, Math. Practice and Theory 1, 1 (1990), 84-88.

[14] S. B. Yakubovich, Index Transforms, World Scisentific Publishing Company, Singapore, New Jersey, London and Hong Kong, 1996.

[15] S. B. YAKUBOVICH, Boundedness and inversion properties of certain convolution transforms, J. Korean Math. Soc. 40, 6 (2003), 999-1014. 
[16] S. B. YAKUBOvich, Integral transforms of the Kontorovich-Lebedev convolution type, Collect. Math. 54, 2 (2003), 99-110.

[17] S. B. Yakubovich, L. E. Britvina, Convolution related to the Fourier and Kontorovich-Lebedev transforms revisited, Integral Transforms Spec. Funct. 21, 4 (2010), 259-276. 